\title{
Anthropometric Measurements of the arm span and their correlation with the Stature of Bengali adult Muslim females
}

\author{
Laila S Z H ${ }^{1}$, Begum J A ${ }^{2}$, Ferdousi $\mathrm{R}^{3}$, Parveen $\mathrm{S}^{4}$, HusainS. M. $\mathrm{S}^{5}$, HolyS Z H $\mathrm{H}^{6}$.
}

\begin{abstract}
:
Anthropometry is the science that deals with the measurement of size, weight and proportion of the human body. Stature or body height is one of the most important and useful anthropometric parameter that determine the physical identity of an individual. The study was done to estimate stature from the arm span on one hundred and fifty Bengali adult Muslim females. Subject was collected from Bangabandhu Sheikh Mujib Medical University, Dhaka and some urban region of Dhaka. The present study showed significant $(p<0.001)$ positive correlation between the stature and the arm span.
\end{abstract}

\section{Introduction:}

Stature are natural heights of a person in an upright position. this can be estimated from arm span ${ }^{1}$. The arm-span frequently used as a basis for estimating age- related loss in stature and as an alternative measure to stature when stature cannot be measured directly due to deformity like kyphosis. lordosis and scoliosis, contracture or missing legs. In these cases the original stature of those people can be estimated by multiplying the dimension of arm span of those sexes or ethnic groups with respective multiplication factor. The multiplication factor can be obtained by making ratio of the stature to the arm span.

\section{Materials and methods:}

The study was predominantly descriptive cross sectional study with some analytical components. It was done on one hundred and fifty Bengali adult Muslim females, 25-30 years approximate by age. 2 Measurement of the stature was taken with a standard anthropometer. The stature was measured as the vertical distance from the vertex to the floor. Measurement was taken by making the subject stand erect on a horizontal resting plane bare footed having the palms of the hands turned inwards and the fingers pointing

1. Assistant Professor, Anatomy Department, Northern International Medical College

2. Associate Professor, Anatomy Department, BSMMU.

3. Professor, Anatomy Department, University Dental College

4. Associate Professor, Physiology Department, Community Based Medical College Bangladesh.

5. Senior Lecture, Anatomy Department, Northern International Medical College.

6. Lecturer, Anatomy Department, University Dental College Correspondence: Dr. Syeda Zamila Hasan Laila downwards. Then, the movable piece of the anthropometer was brought in contact with the vertex in the mid sagital plane. A 3 meter long steel measuring tape was employed for arm-span measurement and the reading was taken to the nearest $0.1 \mathrm{~cm}$. The arm-span was measured while the subject stood erect looking straight ahead with the back against the wall for support. The arms were out stretched at right angles to the body in the coronal plane with the palms facing forwards. The measurement was taken from one middle fingertip to the other middle fingertip, with the tape passing in front of the clavicles ${ }^{3}$. The measurement was recorded in centimeter to the nearest $0.1 \mathrm{~cm}$.

\section{Results:}

The present study showed positive correlation ( $\mathrm{p}$ value $<0.001$ ) between the stature and arm span. The mean stature and mean arm-span were $156.02( \pm 6.13) \mathrm{cm}$ and 160.14 $( \pm 5.41) \mathrm{cm}$ respectively among Bengali adult Muslim female. The stature and other measurements are shown in Table 1.1 along with the multiplication factors used to estimate the stature from these measurements. The table also shows the correlation coefficients ( $r$ ) and $p$ values to reveal the relationships between specific measurements and stature.

Table 1.1 Stature and measurements of the arm span, the multiplication factors for estimating stature from the arm span measurements and correlation of these measurements with stature.

\begin{tabular}{cccll}
\hline Variable & Range (cm) & $\begin{array}{c}\text { Mean } \pm \text { SD } \\
(\mathrm{cm})\end{array}$ & $\begin{array}{l}\text { Mean } \\
\text { multip } \\
\text {-lication } \\
\text { factor* }\end{array}$ & $\begin{array}{l}\text { Correlation of } \\
\text { arm span with }\end{array}$ \\
\cline { 3 - 5 } & & & $\mathrm{r}$ & $\mathrm{p}$ \\
\hline
\end{tabular}

Stature $\quad 145.45-177.50 \quad 156.02+6.13$

$\begin{array}{lllll}\text { Arm span } & 145.05-175.10 & 160.14+5.41 & 0.97 & 0.87\end{array}$

$0.001(\mathrm{~S})$

$N=150 \quad S$ : Significant $r$ : correlation coefficient $p$ : probability ( $\mathrm{p}<0.05$ was considered as significant)

Each multiplication factor is the ratio of the stature to the respective physical measurements. 
Table 1.2 Comparison of the measured stature with the stature estimated from arm span.

\begin{tabular}{llll}
\hline $\begin{array}{l}\text { Measurement } \\
\text { from which } \\
\text { the stature was } \\
\text { estimated }\end{array}$ & Estimated Stature (cm) & $\begin{array}{l}\text { P value representing } \\
\text { the significance of } \\
\text { difference between } \\
\text { the measured stature } \\
\text { and the estimated stature }\end{array}$ \\
\hline Arm span & $140.70-168.85$ & $154.68 \pm 5.05$ & 0.729 (NS)
\end{tabular}

The measured stature ranged from 140.70 to $168.85 \mathrm{~cm}$ with a mean $( \pm \mathrm{SD})$ of $154.68( \pm 5.05) \mathrm{cm}$.

$\mathrm{N}=150 \mathrm{NS}=$ Non-significant .

In the present study there were a significant $(\mathrm{p}<0.001)$ positive correlation between the stature and arm span (Figures 1.01, 1.02)

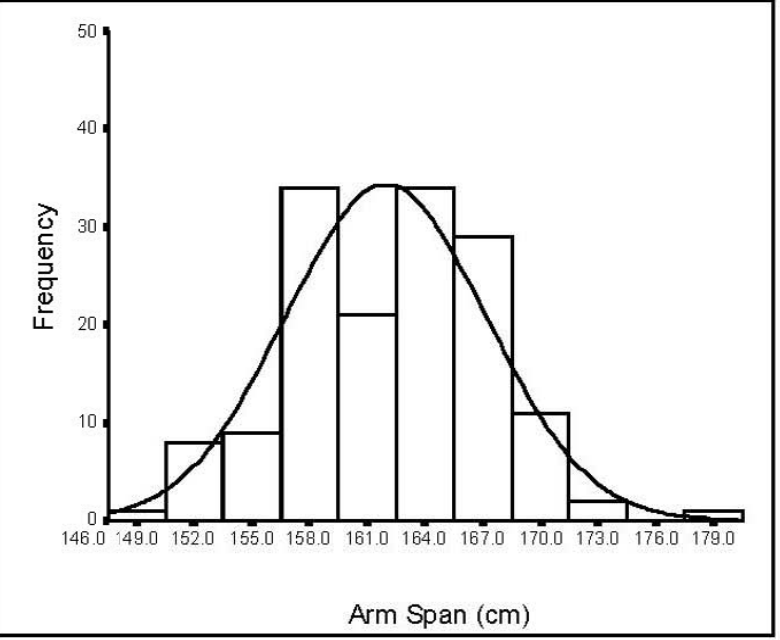

Fig 1.01 Frequency curve showing frequency distribution of arm-span of the Bengali adult Muslim female $(n=150)$

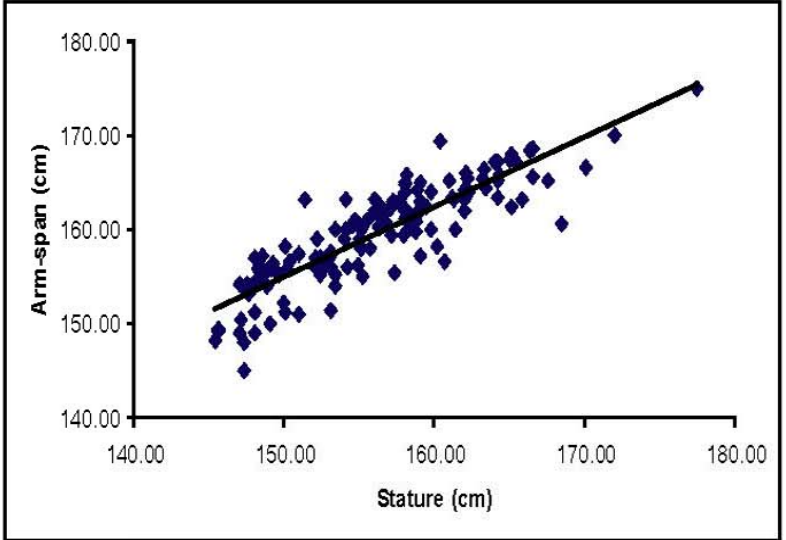

Fig 1.02 Scatter diagram with regression analysis showing significant $(\mathrm{p}<0.001)$ positive correlation $(\mathrm{r}=0.87)$ between the stature and the arm span of the Bengali adult Muslim females $(n=150)$.

\section{Discussion:}

In the present study the mean stature was $156.02( \pm 6.13) \mathrm{cm}$ and the mean arm span was $160.14( \pm 5.41) \mathrm{cm}$. The mean multiplication factor was 0.97 From the present study we found some multiplication factor. Multiplying these multiplication factors with thearm span we found some estimated statures which were correlate with the measured stature. All the measurements in this study were a positive as well as a statistically significant correlation with the stature ${ }^{4}$.

\section{Conclusion:}

From the present study we found some multiplication factors which were helpful for Bengali adult Muslim females for estimation of stature from respective arm span. That may be helpful for those who work in this area especially in the various medical disciplines, anthropologists, beauticians, nutritionists and security experts of Bangladesh.

\section{References:}

1. JASUJA, O.P., AND SINGH, G., 2004. Estimation of stature from hand and phalange length. Journal of Indian Association of Forensic Medicine, 26(3), 100106.

2. ATHWALE, M.C., 1963. Anthropological study of height of forearm bones. American Journal of Physical Anthropology, 21, 105-121.

3. LUCIA, E., LEEMA, F., TESFAYE, F., DEMISSE, F., ISMAIL, S., 2002. The use of arm span measurement to assess the multinational status of adults in four Ethiopian ethnic groups. European Journal of Clinical Nutrition, 56, 91-95.

4. SAXENA, S.K., 1984. A study of correlation and estimation of stature from hand length, hand breadth and sole length. Anthrop Anz., 42 (4), 271-276. 